\title{
2012 ADSA-ASAS Sectional Award
}

\section{Recipient of the Northeast ADSA-ASAS Young Scientist-Educator}

William Burton ("Burt") Staniar was born in Princeton, New Jersey, on August 26, 1974. He received his BA degree in biology from the University of Richmond

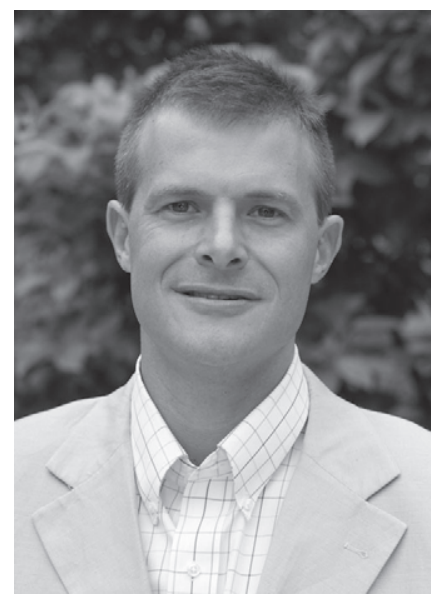

in 1996 and MS and $\mathrm{PhD}$ degrees in animal and poultry sciences from the Virginia Polytechnic Institute and State University at Blacksburg in 1998 and 2002, respectively. From 2002 to 2004, Burt was a postdoctoral associate in equine nutrition at the Middleburg, Virginia, Agricultural Research and Extension Center, where he studied developmental changes in Thoroughbred horses. From 2004 to 2007,

he was an assistant professor of animal science at the Center and, since 2007, he has been assistant professor of animal science at the Pennsylvania State University Department of Dairy and Animal Science.

Widely known throughout the Department and College for his enormous work ethic, determination, and enthusiasm, Staniar carries a heavy teaching load as the primary instructor of three courses (one is writing intensive), and the co-instructor of two additional courses. He is academic advisor for 22 undergraduate students and two graduate students, and he is currently supervising three undergraduate independent studies students. Staniar uses the latest teaching technologies and serves as a valuable resource to other faulty. His instructional methods include interactive lectures that are annotated real-time via a tablet computer and posted on the University coursework management system for student viewing and study. Staniar is on the cutting edge of online delivery of course materials and offers lectures to students at the commonwealth campuses via the World Campus system. He regularly participates in teaching improvement workshops.

Staniar is a firm believer in the direct linkage between undergraduate and graduate education and research. In his desire to integrate these areas and offer research and experiential learning opportunities for students, he created a novel student club, the Penn State Equine Research Team (PSERT), which boasts more than 60 enthusiastic members who are directly involved in Staniar's research projects. Graduate students and senior-level undergraduates help mentor new students in the hands-on methods of equine research and several are listed as co-authors of manuscripts. Faculty in the reproductive physiology group have now replicated Burt's novel idea and established a similar student research club.

Staniar's research efforts are focused on elucidating the effects of diet and metabolic regulation on equine growth and metabolic disease. He is author or coauthor of 19 articles in professional journals and has served on the editorial board of the Journal of Animal Science since 2008 . He works closely with private organizations and industry and has secured over $\$ 235,000$ in grants and gifts for his research. Staniar chairs the steering committee for the major, and he has served on the College's faculty development committee as well as the selection committee for the Schreyer's Honors College of the University. He strives to develop core skills in his students such as communication and problem solving. In his relatively short career, Staniar has had extraordinary success and is extremely deserving of the 2012 Northeast ADSA-ASAS Young Scientist-Educator Award. 